\title{
Resolution of a Common RNA Sequencing Ambiguity by Terminal Deoxynucleotidyl Transferase ${ }^{1}$
}

\author{
Dan C. DeBorde, ${ }^{*}$ Clayton W. Naeve, $\dagger$ M. Louise Herlocher, ${ }^{*}$ \\ AND HUNEIN F. MAASSAB* \\ *Department of Epidemiology, School of Public Health, University of Michigan, 109 Observatory, Ann Arbor, \\ Michigan 48109, and $\dagger$ Department of Virology and Molecular Biology, \\ St. Jude Children's Research Hospital, Memphis, Tennessee 38101
}

Received April 21, 1986

\begin{abstract}
One of the more common ambiguities which arise when using reverse transcriptase and dideoxynucleotide-chain termination to sequence RNA is a radioactive band of cDNA that extends over all four lanes on a sequencing gel. The adjacent sequences both above and below the band are not affected. Assuming then, that these ambiguities are caused by the termination of the DNA polymerase activity of reverse transcriptase for reasons other than the insertion of a dideoxynucleotide in the growing cDNA chain, terminal deoxynucleotidyl transferase should be able to continue to add deoxynucleotides to these products after the sequencing reaction is complete. It does, clearing the improperly terminated cDNA from these pileup sites, revealing the correct sequence. This technique can also be used to identify the template RNA's 5'-terminal base, although far more units of terminal deoxynucleotidyl transferase are required. (1) 1986 Academic Press, lnc.

KEY WORDS: RNA sequencing; terminal deoxynucleotidyl transferase; dideoxynucleotides; revcrse transcriptasc; cDNA; chain termination.
\end{abstract}

Primer extension and chain termination sequencing of RNA using reverse transcriptase, specific oligodeoxynucleotide primers, and dideoxynucleoside triphosphates (ddNTP) ${ }^{2}$ can provide 300-400 nucleotides of sequence per primer. Within that length of sequence are usually sites at which all four lanes $(\mathrm{A}, \mathrm{C}, \mathrm{G}$, and $\mathrm{T}$ ) contain labeled cDNA product. These sequence ambiguities which resemble bands

\footnotetext{
${ }^{1}$ The work in this paper was supported by Contract No. 1-AI-52564, National Institute of Allergy and Infectious Diseases, Development and Application Branch, Bethesda, Md. 20892, and by a Biomedical Research Support Grant, RR 05584-21.

${ }^{2}$ Abbreviations used: ddNTP, dideoxynucleoside 5'-triphosphate; ddATP, dideoxyadenosine 5 'triphosphate; ddCTP, dideoxycytidine 5'-triphosphate; ddGTP, dideoxyguanosine 5'-triphosphate; ddTTP, dideoxythymidine 5'triphosphate; Klenow fragment, DNA polymerase I, large fragment; TdT, terminal deoxynucleotidyl transferase; DTT, dithiothreitol; silane, dimethyldichlorosilane; $\gamma$-silane, $\gamma$-(methacryloxy)propyltrimethoxysilane; NP, nucleoprotein; M, matrix protein.
}

across all four gel lanes might arise in a number of ways. Legitimate cDNA bands in all four lanes would result from ddNTP termination of the polymerizing cDNA due to microheterogeneity within the population of viral template RNA; i.e., a nonhomogenous population of RNA molecules are present which vary in sequence at only these sites. Artifactual bands can result in several ways: compression of the cDNA products caused by base pairings within the cDNA affecting their electrophoretic mobility, or site-specific termination of the DNA polymerase activity of the reverse transcriptase, unrelated to the insertion of a ddNTP within the extending cDNA chain. The accurate determination of the sequence at these sites is impossible unless the ambiguity is resolved.

Similar problems exist for the Sanger dideoxy-chain termination method for DNA (1) and most current methods for their resolution have been tested with DNA templates. Klenow 
fragment is generally the enzyme used for the primer extension on a DNA template, but reverse transcriptase can also be used. It has been suggested that sequencing difficulties due to improper chain termination might be overcome by using both enzymes (separately) when necessary, since the bands can occur at slightly different sites with each enzyme (2). The correct sequence can usually be determined by using the DNA sequence complementary to the template, because even though similar problems exist for both strands, they generally occur at different sites. In direct RNA sequencing, however, the availability of a complementary sequence, either RNA or DNA, may be problematic. Recently, a troubleshooting guide was published for the Sanger dideoxy-chain termination method using DNA, $\left[{ }^{35}\right.$ S $]$ deoxyadenosine, $5^{\prime}(\alpha$-thio)-triphosphate, and Klenow fragment which showed that bands in all four lanes were sometimes resolved by deleting $\mathrm{NaCl}$ from the reaction (3). The lack of $\mathrm{NaCl}$ destabilizes regions of secondary structure in the DNA. In some cases, where these procedures were not successful, Ornstein and Kashdan (1985) also suggested using higher reaction temperatures $\left(42^{\circ} \mathrm{C}\right.$ or $\left.55^{\circ} \mathrm{C}\right)$ in conjunction with the absence of $\mathrm{NaCl}$ to increase the DNA destabilization. If that failed, like Smith (1980), they also recommended the use of reverse transcriptase which might terminate at a site different than that for the Klenow fragment. Thus, current solutions generally attack the problem by changing the reaction conditions or components with either no guarantee of success or at the expense of a new preparation of primer and/or template.

During the direct sequencing of influenza B cold-adapted and wild-type B/Ann Arbor/ 1/66 influenza virus RNA, we frequently encountered sites at which all four lanes $(A, C$, $G$, and $T$ ) contained labeled cDNA, sometimes as many as eight, within the 250 - to 400 base sequence following a specific primer. The frequency and extent of these ambiguities argued against an origin due to variation within the RNA template. Microheterogeneity, if present, would more likely involve only one other base, possibly two, but not always all four possible bases at every occurrence. No evidence for improper spacing above or below the band was observed, and comparison with the known sequence of a similar virus, B/Lee/ 40 , indicated that only one base position was involved, ruling out compressions as the source of ambiguity. Thus, these bands probably resulted from the premature termination of the DNA polymerase activity of the reverse transcriptase prior to the insertion of a ddNTP in the growing cDNA chain.

Improper termination would result in cDNA in all four lanes that had free $3^{\prime}-\mathrm{OH}$ ends and only one of the four lanes would also contain cDNA product that was terminated by its specific ddNTP. TdT should be able to add dNTP to the cDNA with the free $3^{\prime}-\mathrm{OH}$ ends, thus moving the spurious bands out of their present positions revealing the correct sequence at that site. We demonstrate that the addition of TdT during the chase portion of standard sequencing reactions results in the resolution of these common and troublesome ambiguities with a minimum of effort and expense. The concentration of enzyme required, and the application of this technique to the resolution of the 5 '-terminal vRNA nucleotides are also examined.

\section{MATERIALS AND METHODS}

Materials. Oligodeoxynucleotide primers are made by one of the authors, C. W. Naeve, on an Applied Biosystems Model 380A DNA synthesizer. Reverse transcriptase is the standard preparation from Life Sciences, Inc., St. Petersburg, Florida, and the ddNTPs are from Boehringer Mannheim, Indianapolis, Indiana. The TdT is from Bethesda Research Laboratories, Gaithersburg, Maryland. Silane and $\gamma$ silane are from Sigma Chemical Company, St. Louis, Missouri.

Buffers. Buffer A: 0.1 M Tris-HCl, pH 7.4, $0.1 \mathrm{M} \mathrm{NaCl}$, and $0.001 \mathrm{M}$ EDTA. Buffer B: 5 $\mathrm{M}$ guanidine thiocyanate, $50 \mathrm{mM}$ Tris- $\mathrm{HCl}$, pH 7.5, 10 mM EDTA, and 5\% 2-mercapto- 
ethanol. Buffer C: $0.1 \mathrm{M}$ Trizma base, $0.1 \mathrm{M}$ boric acid, and 2 mM EDTA. Buffer D: 100 $\mathrm{mM}$ potassium cacodylate, $\mathrm{pH} 7.2,2.0 \mathrm{mM}$ $\mathrm{CoCl}_{2}, 0.2 \mathrm{~mm}$ DTT. Buffer E: $100 \mathrm{~mm}$ sodium cacodylate, $\mathrm{pH} 7.0,2.0 \mathrm{mM} \mathrm{MnCl}_{2}, 0.1$ mM DTT.

Viruses. Stocks of cold-adapted B/Ann Arbor/1/66 virus were prepared by limiting-dilution passage in 10- to 11 -day-old embryonated chicken eggs for $72 \mathrm{~h}$ at $33^{\circ} \mathrm{C}$. Virus for the preparation of viral RNA was prepared by inoculating 60 to 100 embryonated eggs with $0.1 \mathrm{ml}$ of a one-thousand-fold dilution of virus stock in Hanks' buffered salt solution, Grand Island Biological Company, Grand Island, New York, and incubating the infected eggs for $72 \mathrm{~h}$ at $33^{\circ} \mathrm{C}$. The allantoic fluid was harvested and clarified at $1,000 \mathrm{~g}$ for $15 \mathrm{~min}$ at $4^{\circ} \mathrm{C}$. The supernatant was put into $500-\mathrm{ml}$ centrifuge bottles and underlayered with $30 \%$ $(w / v)$ sucrose solution in Buffer $A$. The virus was pelleted through the sucrose cushion at $8,500 \mathrm{rpm}$ for $17 \mathrm{~h}$ at $4^{\circ} \mathrm{C}$. The pellet was resuspended in Buffer $A$, homogenized by 4 to 5 passages through a 26-gauge needle, layered onto a $5-20 \%(w / w)$ sucrose gradient in Buffer $\mathrm{A}$, and centrifuged for $35 \mathrm{~min}$ in an SW25.1 rotor at $20,000 \mathrm{rpm}$ at $4^{\circ} \mathrm{C}$. The virus band in the center of the gradient was then diluted with at least $3 \mathrm{vol}$ of Buffer $A$ and pelleted at $22,500 \mathrm{rpm}$ for $2 \mathrm{~h}$ at $4^{\circ} \mathrm{C}$ in the Type 30 rotor.

Isolation of virul $R N A$. The virus pellet was resuspended in $0.3 \mathrm{ml}$ of $0.3 \mathrm{M}$ sodium acetate. Proteinase $\mathrm{K}(300 \mu \mathrm{g})$ was added to the suspension and incubated for $10 \mathrm{~min}$ at $37^{\circ} \mathrm{C}$. $N$-lauroyl sarcosine was added to a final concentration of $0.5 \%$ and the samples were incubated an additional $10 \mathrm{~min}$ at $37^{\circ} \mathrm{C}$. The sample was then mixed with Buffer $B$ and the RNA pelleted through a $5.7 \mathrm{M} \mathrm{CsCl}$ cushion as described by McGookin (1984). The pellet was resuspended in $0.2 \mathrm{ml}$ of $0.3 \mathrm{M}$ sodium acetate, ethanol precipitated overnight at $4^{\circ} \mathrm{C}$ with $3 \mathrm{vol}$ of $95 \%$ ethanol. The sample was pelleted out of ethanol in a tabletop microfuge, and resuspended in $50 \mathrm{ml}$ of deionized sterile water. The RNA concentration was deter- mined spectrophotometrically at $260 \mathrm{~nm}$, and the concentration adjusted to $1 \mathrm{mg} / \mathrm{ml}$. Viral RNA yield was roughly $1 \mu \mathrm{g}$ per egg. The RNA was frozen under liquid $\mathrm{N}_{2}$ until use.

$R N A$ sequencing reactions. The RNA sequencing reactions were essentially identical to those given by Air (1979) with only minor differences relating to the ddNTP concentrations. These were empirically determined to generate usable sequence data for approximately 400 bases beyond the primer. Four microliters of reaction mix were combined with $1 \mu$ l of RNA-primer mix to give the following components and their concentrations: Tube A, $50 \mathrm{mM}$ Tris- $\mathrm{HCl}(\mathrm{pH} 8.0), 50 \mathrm{mM} \mathrm{KCl}, 5$ $\mathrm{mM} \mathrm{MgCl} 2,10 \mathrm{mM}$ DTT, $3 \mu \mathrm{M}$ dATP, $50 \mu \mathrm{M}$ $\mathrm{dCTP}, 50 \mu \mathrm{M}$ dGTP, $50 \mu \mathrm{M}$ dTTP, $5 \mu \mathrm{Ci}$ $\left[{ }^{32} \mathrm{P}\right] \mathrm{dATP}, 1.25 \mu \mathrm{M}$ ddATP, $125 \mathrm{ng}$ RNA, and $12.5 \mathrm{ng}$ of primer; Tube $\mathrm{C}$, same as Tube $\mathrm{A}$, except $10 \mu \mathrm{M}$ dCTP, $2.5 \mu \mathrm{M}$ ddCTP, and no ddATP; Tube G, same as Tube A, except 10 $\mu \mathrm{M}$ dGTP, $3.0 \mu \mathrm{M}$ ddGTP, and no ddATP; Tube $\mathrm{T}$, same as Tube A, except $10 \mu \mathrm{M}$ dT $\Gamma$, $7.5 \mu \mathrm{M}$ ddTTP, and no ddATP. The RNA and primer mix was prepared as in Air (1979) prior to its addition to the reaction mixes. The completed mixes are incubated at $37^{\circ} \mathrm{C}$ for $30 \mathrm{~min}$. This reaction incubation was followed by a chase, with $1 \mu \mathrm{l}$ of a mixture of dATP, dCTP, dGTP, and dTTP (each at $1 \mathrm{mM}$ ) added to each tube, and the reaction incubated an additional $30 \mathrm{~min}$ at $37^{\circ} \mathrm{C}$. When TdT was included in the reaction, it was added with the chase dNTPs, generally in a volume of $1 \mu \mathrm{l}$ and never more than $2 \mu \mathrm{l}$. The reaction was halted by freezing at $-20^{\circ} \mathrm{C}$. Prior to electrophoresis, $10 \mu \mathrm{l}$ of formamide-dye mixture (5) was added to each sample which was then immersed at $100^{\circ} \mathrm{C}$ for $3 \mathrm{~min}$ with the top open. After boiling, 3-4 $\mu \mathrm{l}$ of each sample were loaded per gel lane.

Polyacrylamide gels. The polyacrylamide gels were made using stock acrylamide: $N^{\prime}, N^{\prime}$ methylene-bis-acrylamide (38:2) and were either $8 \%$ or $6 \%$ polyacrylamide gels, with $7 \mathrm{M}$ Urea, and Buffer $C$. Gel dimensions were 35 $\mathrm{cm} \times 43 \mathrm{~cm} \times 0.4 \mathrm{~mm}$. Combs were 64-well sawtooth combs, and both combs and appa- 
ratus were from International Biotechnologies Incorporated, New Haven, Connecticut.

Phenol-chloroform extraction of cDNA. This extraction procedure was only used in an effort to eliminate the ambiguity that results at the 5 '-end of the template. It was not part of the routine sequencing reaction procedure. Completed sequence reactions, either in part (thirds or halves) or whole, were mixed with $100 \mu 1$ of $0.3 \mathrm{M}$ sodium acetate with $0.2 \%$ SDS and then extracted with $100 \mu \mathrm{l}$ of redistilled phenol and $100 \mu \mathrm{l}$ of chloroform solution (chloroform:isoamyl alcohol, 24:1). The aqueous phase was reextracted with $200 \mu$ l of chloroform solution, and then the aqueous phase transferred to a new tube and extracted twice with ether. The residual ether was removed by passing $\mathrm{N}_{2}$ gas over the sample. The samples were precipitated at $-70^{\circ} \mathrm{C}$ for $15 \mathrm{~min}$ with $300 \mu \mathrm{l}$ of ethanol, and then pelleted in a microcentrifuge for $10 \mathrm{~min}$ at $13,000 \mathrm{rpm}$. The pellet was washed once with $95 \%$ ethanol and dried in a vacuum concentrator (Savant Instruments, Inc., Hicksville, N.Y.).

Autoradiography. After electrophoresis was complete the gels were dried onto the large glass plates in an oven at $70^{\circ} \mathrm{C}$ for approximately 1 to $1.5 \mathrm{~h}$, cooled to room temperature, and exposed to XAR5, X-ray film (Kodak, Rochester, N.Y.) for $16 \mathrm{~h}$. The large glass plates had been pretreated with $20 \mathrm{ml}$ of ethanol containing $60 \mu \mathrm{l}$ of $\gamma$-silane and 600 $\mu \mathrm{l}$ of $10 \%$ acetic acid to bind the gels to the glass plate during drying. At the same time, the small plates were pretreated with $5 \%$ silane in chloroform to inhibit gels from sticking to them.

\section{RESULTS}

Figure 1 shows several ambiguities found in the sequence of B/Ann Arbor/1/66 cold adapted influenza virus using a 15-nucleotidelong specific primer starting at position 429 in the viral NP RNA. Lanes 9-12 contain samples from the standard sequencing reaction (conditions given under Materials and Methods). Lanes 13-16 contain samples from the

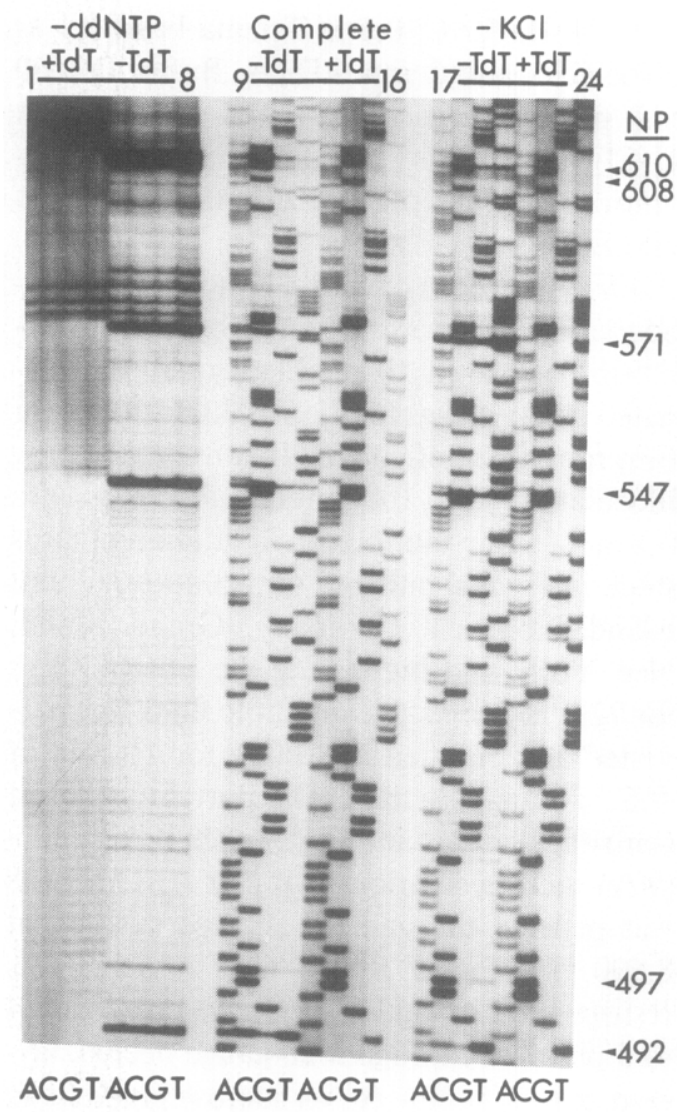

FIG. 1. Sequence ambiguities appearing in cDNA sequences prepared from cold-adapted B/Ann Arbor/1/66 viral RNA primed with a specific 15-nucleotide-long primer beginning at position 429 in the NP gene. The sequencing gel was an $8 \%$ polyacrylamide gel prepared as under Materials and Methods, and electrophoresed for 3 $h$ at $1750 \mathrm{~V}$, constant voltage. Lanes 1-8 are standard sequencing reactions without ddNTPs. Lanes 9-16 are standard sequencing reactions. Lanes 17-24 are standard sequencing reactions without $\mathrm{KCl}$. Lanes $1-4,13-16$, and 21-24 had 3.5 units of TdT added to the sequencing reactions for the chase period of $1 \mathrm{~h}$. Numbers along the right side represent the nucleotide positions of sequence ambiguities. Letters along the bottom denote the particular reaction in that lane, based on the ddNTP present for lanes 9-24, or omitted in lanes 1-8.

standard reactions with $0.25 \mu \mathrm{l}$ (3.5 units) of TdT added at the start of a 1-h chase period. It is apparent that the spurious bands have been removed. One method that is often used in an attempt to determine the sequence at these sites relies on repeated sequencing experiments, from which the investigator deter- 
mines that one particular lane always contains the darkest band, and decides that that is the correct nucleotide. While this method may give the right answer many times, it is possible to err. By band intensity, lanes 9-12 would indicate that the correct nucleotide at position 571 was a $C$, but after TdT treatment, it becomes obvious that it is a T (lanes 13-16 and 21-24). The number of nucleotides attached by the TdT under these conditions is so random that the band disappears rather than moving up to a new position. If the TdT is added to the chase together with $1 \mu$ l of Buffer $D(5 X)$, or if there is a large amount of nondideoxynucleotide-terminated cDNA, a ladder may appear above the band in each lane (data not shown). If the ladder becomes too dark, interfering with further sequences, reactions with and without TdT have to be performed to sequence that region of RNA. Lanes 1-4 and 5-8 are standard reactions without ddNTPs. Lanes 1-4 had 3.5 units of TdT added during the chase. It was apparent that the strong bands appearing in all four lanes (5-8) represent the same bands interfering with the determination of the sequence, and that they could be moved out of their normal position by the addition of TdT. There were three minor bands (just above position 571) apparent in the reactions without ddNTPs (lanes 18 ) that were not removed by the addition of TdT (lanes 1-4 and 13-16). However, these bands did not interfere in the determination of the sequence (lanes 9-12).

Reverse transcriptase does not require monovalent cations, although low concentrations (generally about $50 \mathrm{mM}$ ) of $\mathrm{K}^{+}$or $\mathrm{Na}^{+}$ may stimulate activity (6). Our standard reaction contains $\mathrm{KCl}$ rather than $\mathrm{NaCl}$. When $\mathrm{KCl}$ was left out of the standard reaction [similar to the deletion of $\mathrm{NaCl}$ for the Klenow fragment reaction suggested by Ornstein and Kashdan (1985)] no difference was noted either in the intensity of the ambiguous bands or the standard bands (Lanes 17-24, Fig. 1). Lack of a monovalent cation did not overcome the sequence ambiguity (lanes 17-20), but the subsequent addition of TdT did (lanes 21-24).
The minimum concentration of TdT required to eliminate the spurious bands was determined (Fig. 2). The concentration needed depended on the amount of cDNA with free $3^{\prime}-\mathrm{OH}$ ends present in the bands. For a typical reaction containing $0.1-0.2 \mu \mathrm{g}$ of total influenza RNA (all eight virion RNA segments), $12.5 \mathrm{ng}$ of primer, and 6 units of reverse transcriptase; 3.5 units of terminal transferase was sufficient to eliminate all ambiguities in the nucleoprotein RNA sequence following the NP.429 primer (Fig. 2, lanes 5-8). Some bands

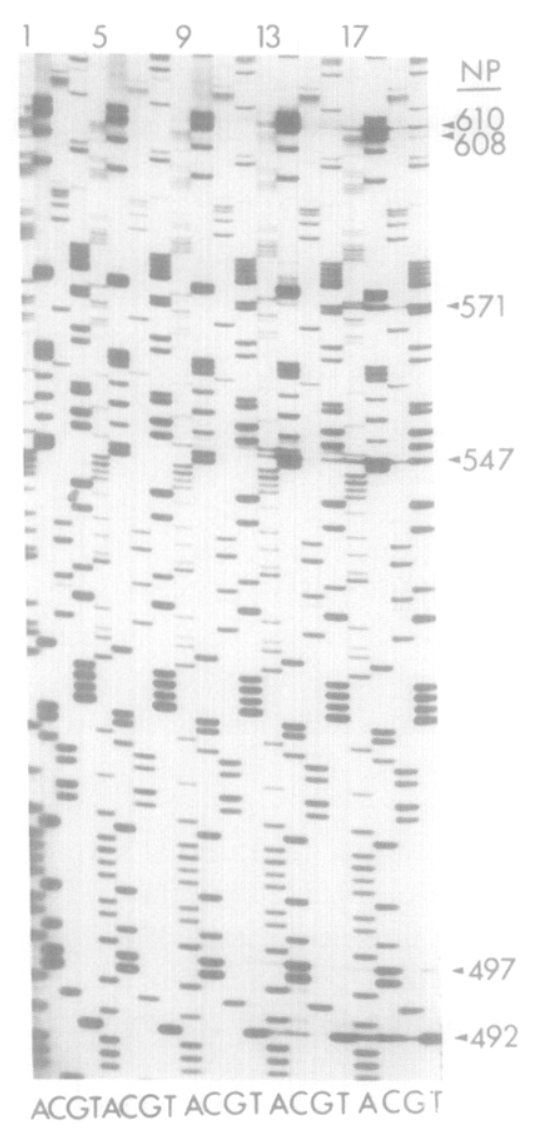

Fig. 2. Determination of the minimum Td7 concentration sufficient to eliminate the sequence ambiguities seen in Fig. 1. The RNA, oligodeoxynucleotide primer, and electrophoresis conditions are identical to Fig. 1. Lanes $1-4,5-8,9-12$, and 13-16 are all standard sequencing reactions with the respective concentrations of $\mathrm{TdT}$ added as under Materials and Methods: 7 units, 3.5 units, 1.4 units, and 0.7 units. Lanes $17-20$ were standard sequencing reactions with no added TdT. 
were removed with only 1.4 units of enzyme (Fig. 2, lanes 9-12). As much as 15-20 units of TdT may be used if desired without hindering the sequencing reaction or subsequent electrophoresis. Reactions containing the same series of TdT concentrations used in Fig. 2, but in the presence of Buffer $D(1 \times)$, gave identical results, except that at the highest enzyme concentration, ladders appeared above the sites of ambiguity (data not shown).

The 5'-ends of the vRNAs represent a special case of sequence ambiguity, presumably caused by the termination of the polymerization activity of reverse transcriptase due to the end of template, not due to secondary structure. The conditions used to eliminate the internal bands shown in Figs. 1 and 2 were not sufficient to resolve the terminal nucleotide. The 5'-terminal nucleotide at the end of the $M$ vRNA was resolved with TdT added at the chase, only when a minimum of 21 units of TdT $(1.5 \mu \mathrm{l})$ were added to one-third part ( 2 $\mu l$, after addition of chase) of a standard reaction without $\mathrm{KCl}$ (Fig. 3). It can be seen from lanes 5-8, in Fig. 3, that this higher concentration of TdT enzyme, while identifying the terminal nucleotide, also has begun to affect the resolution of the cDNA, causing them to blur. This fuzziness was later determined to result from the increased salt concentration due to the buffer in which the TdT was stored (data not shown). Because this amount of enzyme was in great excess over the amount required to eliminate the internal sequence ambiguities, we decided to see if the TdT reaction could be optimized to use less enzyme. The cDNA products from one-third of a standard reaction and chase were phenol-chloroform extracted to remove the reverse transcriptase, and ethanol precipitated to optimize the buffer conditions for TdT tailing. Thus, $100 \mu \mathrm{l}$ of 0.3 $\mathrm{M}$ sodium acetate, $0.2 \%$ SDS, was added to each reaction mixture and phenol-chloroform extracted (see Materials and Methods). Each sample was ethanol precipitated by the addition of $3 \mathrm{vol}$ of $95 \%$ ethanol at $-70^{\circ} \mathrm{C}$ for at least $15 \mathrm{~min}$. The samples were pelleted,

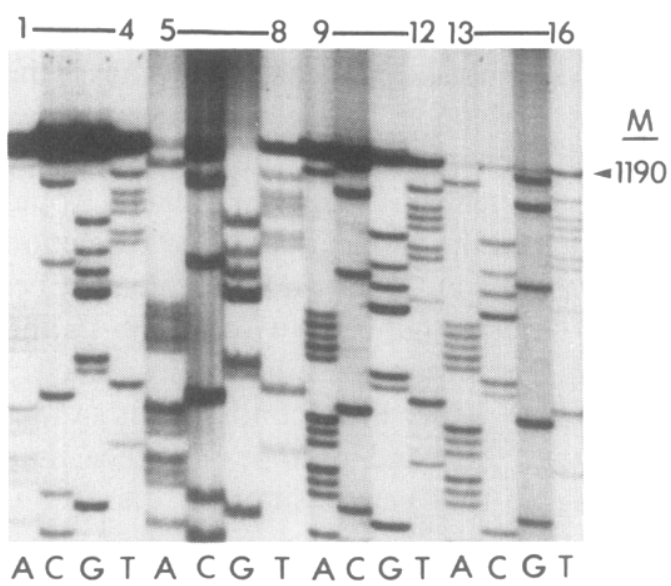

FIG. 3. Sequence ambiguity appearing at the 5 -terminal nucleotide of the viral M RNA in cDNA prepared from cold-adapted B/Ann Arbor/1/66 viral RNA primed with a specific 15-nucleotide-long primer beginning at position 1050 in the $M$ gene. The sequencing gel was a $6 \%$ polyacrylamide gel prepared as under Materials and Methods, and electrophoresed for $2.5 \mathrm{~h}$ at $1750 \mathrm{~V}$, constant voltage. Lanes 1-4 are the standard sequencing reactions. Lanes 5-8 are the standard reactions with 21 units of TdT added at the chase period as under Materials and Methods. Lanes 9-16 are standard reactions which have been phenolchloroform extracted, ethanol precipitated, and resuspended in Buffer $E$ with TdT cnzyme and $1 \mathrm{mM}$ dGTP. Lanes 9-12 had 14 units of TdT, and lanes 13-16 had 21 units of TdT. These reactions were subsequently ethanol precipitated, resuspended in Buffer $\mathrm{C}$ and loading solution, boiled, and loaded onto the sequencing gel. The number 1190 along the right side indicates the terminal nucleotide position. Letters along the bottom denote the particular reaction in that lane, based on the ddNTP present.

washed once with $95 \%$ ethanol, and dried under vacuum at room temperature. They were resuspended in water, boiled for 1 min, quick chilled on ice, and made $1 \times$ in Buffer $E$, together with $1 \mathrm{mM} \mathrm{dGTP}$, and 14 or 21 units of TdT in a final volume of $20 \mu \mathrm{l}$. These conditions have been shown to be optimal for tailing the highest percentage of DNA substrate, whether $3^{\prime}$-protruding, blunt end, or 3'recessive termini are present $(8)$. The samples were incubated at $37^{\circ} \mathrm{C}$ for $1 \mathrm{hr}$, mixed with $100 \mu \mathrm{l}$ of $0.3 \mathrm{M}$ sodium acetate, ethanol precipitated, and dried as above. The dried cDNA was resuspended in $6 \mu$ l of Buffer $C$ together 
with $10 \mu$ l of formamide dye mixture (5), immersed in a boiling water bath for 3 min with the tops open, and 3-4 $\mu$ l loaded onto the appropriate gel. Only the higher of the two TdT enzyme concentrations was able to remove most of the obscuring cDNA so that the terminal position was identified by a band remaining in the ddTTP-terminated reaction, as expected for an influenza B virus (7). Thus, in spite of the phenol-chloroform extraction and the optimization of tailing reaction conditions, excess TdT was still required to resolve the nucleotide at this terminal position. The amount of obscuring cDNA at this terminal position is probably more abundant than that at the internal positions, thus requiring more enzyme to tail every free $3^{\prime}-\mathrm{OH}$ end. However, in some experiments performed on the same day with the same reagents, the intensity of the terminal bands did not appear to be darker than some of the internal bands (especially those in Fig. 1, lanes 1-8, without ddNTPs present), yet they still required excess $\mathrm{TdT}$ to resolve (data not shown). It may be that this site is less available to the TdT enzyme than the others.

\section{DISCUSSION}

The application of the Sanger chain-terminating sequencing method to the direct sequencing of RNA has proven especially valuable for the determination of viral RNA sequences. Direct sequencing on a population of RNA molecules provides data representing the most abundant sequence, identifies any significant microheterogencity that may cxist, and eliminates the worry that a sequence derived from a particular cDNA clone does not represent the consensus sequence. The ambiguities that derived from this sequencing method probably account for less than 1 to $2 \%$ of the total number of bases sequenced, but their resolution often entails as much expense and more effort than required for the determination of the other $98-99 \%$. After se- quencing six different RNA genes of influenza $B$ virus, all but one site of ambiguity has been resolved by the use of TdT. The amount of TdT required for resolution is related to the amount of non-ddNTP-terminated cDNA present, and the use of one-half or one-third the normal sequencing reaction volume allows the corresponding reduction of enzyme units. In general, almost all ambiguities in the internal sequences have been resolved with no more than 3.5 units of TdT per reaction.

An adaptation of this method also allows one to determine the 5 -terminal vRNA base, although far more enzyme is required. Other biochemical methods are available to determine the identity of this terminal base, but for influenza virus they require the isolation of individual RNA segments, which entails more effort and expense than the TdT method. The reason that the terminal sequence is so refractive to TdT resolution is unknown, but our results suggest that both the quantity of improperly terminated cDNA and possibly the secondary structure of the cDNA may be involved, since interference by reverse transcriptase would have been eliminated following phenol-chloroform extraction.

The use of TdT provides an easy, rapid, and economical method, requiring no change in the major reaction components, nor extensive subsequent manipulations to resolve a common sequence ambiguity. The quality of sequence data provided by the incorporation of this technique into the standard procedures will allow one to have confidence in data pointing to the existence of micro-heterogeneity, which before may have been considered to be an artifact of the reaction. The addition of the TdT enzyme may either be done as a general procedure, being added to every reaction, or if the economics dictate and the number of ambiguities are small, normal sequencing procedures may be performed, sites of ambiguities identified, and specific reactions performed with TdT as needed. We have found the use of TdT to be an invaluable aid in resolving ambiguities in RNA sequencing. 


\section{ACKNOWLEDGMENTS}

We thank Susan Peters for her expert preparation of viral RNA and Deanna Williams for her expert preparation of oligodeoxynucleotide primers.

\section{REFERENCES}

1. Sanger, F., Nicklen, S., and Coulson, A. R. (1977) Proc. Natl. Acad. Sci. USA 74, 5463-5467.

2. Smith, A. J. H. (1980) in Methods in Enzymology (Grossman, L., and Moldave, K., eds.), Vol. 65, pp. 560-580, Academic Press, Orlando, Fla.

3. Ornstcin, D. L., and Kashdan, M. A. (1985) Biotechniques 3, 476-483.
4. McGookin, R. (1984) in Methods in Molecular Biology (Walker, J. M., ed.), Vol. 2, pp. 113-116, Humana Press, Clifton, New Jersey.

5. Air, G. M. (1979) Virology 97, 468-472.

6. Kacian, D. L. (1977) in Methods in Virology (Maramorosch, K., and Koprowski, H., eds.), Vol. VI, pp. 143-184, Academic Press, Orlando, Fla.

7. Air, G. M., and Compans, R. W. (1983) in Genetics of Influenza Viruses (Palese, P., and Kingsbury, D. W., eds.), pp. 280-304, Springer-Verlag, New York.

8. Deng, G., and Wu, R. (1983) in Methods in Enzymology (Wu, R., Grossman, L., and Moldave, K., eds.), Vol. 100, pp. 96-116. Academic Press, Orlando, Fla. 